\title{
Repeat induced abortion and associated factors among reproductive age women who seek abortion services in Debre Berhan Town Health Institutions, Central Ethiopia, 2019
}

Geremew Kindie Behulu ( $\nabla$ geremewkindie@gmail.com )

Endegena Abebe Fenta

Debre Berhan University

Getie Lake Aynalem

University of Gondar

Research note

Keywords: Repeated abortion, Debre Berhan, Ethiopia

Posted Date: April 23rd, 2020

DOI: https://doi.org/10.21203/rs.3.rs-24151/v1

License: (c) (i) This work is licensed under a Creative Commons Attribution 4.0 International License.

Read Full License

Version of Record: A version of this preprint was published at BMC Research Notes on August 13th, 2019. See the published version at https://doi.org/10.1186/s13104-019-4542-3. 


\section{Abstract}

Objective: To assess the magnitude and associated factors of repeat induced abortion among women aged from 15-49 who seek abortion care services in the health institutions of Debre Berhan town, Central Ethiopia, 2019

Results: This study shows that the prevalence of repeat induced abortion among 355 respondents was to be $20.3 \%$. Those who reported as they had more than one partner in the last 12 preceding months, $(A O R=7.3,95 \% \mathrm{Cl}: 3.21,16.46)$, Age of the first sexual intercourse less than 18 years ( $A O R=6,95 \% \mathrm{Cl}$ : $2.54,13.95)$ and Perceiving abortion procedure as it was not painful (AOR=7.7, 95\% Cl: 2.9, 20.6) were variables positively associated with the repeatedly induced abortion among women who sought abortion services.

\section{Introduction}

Repeat-induced abortion defined as those reporting at least one previous induced abortion (1). Abortion is a sensitive and controversial issue with religious, moral, cultural, and political scopes. It is also a public health issue in many parts of the world. More than one-fourth of the world's people live in rural areas where the procedure is prohibited or allowed only to preserve the woman's lifetime. However, irrespective of legal status, abortions still occur, and nearly half of them are performed by an unskilled practitioner or in less than sanitary conditions, or both (2).

The World Health Organization (WHO) estimates that worldwide 210 million women get pregnant each year and that nearly two-thirds of them, or roughly 130 million, deliver live babies. The remaining one-third of pregnancies end in miscarriage, stillbirth, or induced abortion (2). Statistical reports show that around $13 \%$ of maternal deaths is contributed by unsafe abortion in the globe (3). Induced abortion is frequently a consequence of inadequate contraception and the reasons not to use contraception originate from lack of correct information (4)

Repeat abortion, or getting more than one pregnancy termination, is bound in a vicious cycle with repeat unintended pregnancy (5). Women who have had a recent abortion are more potential to discontinue contraceptive use during a 1-year follow up period, and both current and other previous abortion clients are more likely to have a repeat unintended pregnancy during that period (6). The incidence of women looking for induced abortion and particularly those seeking a repeated induced abortion is an essential indicator of the frequency with which women have unintended pregnancies, and it can point to gaps in contraceptive services and effective contraceptive use (7)

Despite the high incidence of repeat abortions and their consequences, research on it is scarce in low and middle-income countries, particularly in Ethiopia. Abortion is currently legal in Ethiopia in cases of rape, incest, or fetal impairment. Also, a woman can legally terminate a pregnancy if her life or her child's life is at risk, or if continuing the pregnancy or giving birth threatens her life. A woman may also terminate a pregnancy if she is unable to bring up the child, owing to her status as a minor or to a physical or mental 
infirmity since 2005 and the contraceptive coverage reached 36\% in 2016 (8). The abortion rate among childbearing age women was about 23 per 1,000 women aged 15-44 in 2008 (9).

The magnitude of repeat abortion in Ethiopia is not known; this study seeks to help enlighten. The overall prevalence of unintended pregnancy in Ethiopia is about $42 \%$. Among an annual 3.27 million estimated pregnancies, half a million ends up in abortion (10).

As far as our knowledge is concerned, there are no studies done on the magnitude and associated factors of repeat induced abortion in Amhara region, so the aim of this study was to determine the prevalence and associated factors of repeat induced abortion among the reproductive age group of women at the health institutions of Debre Berhan town, Central Ethiopia.

\section{Methods}

Study design and setting: An institutional based cross-sectional study design was conducted among the reproductive age group of women at the health institutions in Debre Berhan town. The town is found in North Shewa Zone, North West Ethiopia, Amhara region which is about 120 kilometers from Addis Ababa (capital city of Ethiopia). Based on the 2007 national census carried on by the Central Statistical Agency of Ethiopia (CSA), this town has total residents of 65,231 , of whom 31,668 are men and 33,563 women. The most of the peoples practiced Ethiopian Orthodox Christianity, with $94.12 \%$ reporting that as their religion, while $3.32 \%$ of the population said they were Muslim and $2.15 \%$ were Protestants (15). There are two governmental and one private health institutions in the town.

\section{Sample size and sampling procedure}

Sample size calculation was done by using a single proportion population formula by considering the following assumptions: $p=0.16$ from previous study $(11), 95 \% \mathrm{Cl}$, and $4 \%$ marginal error. Then, using the formula $n=((Z a / 2) 2 p(1-p)) / W 2$.

Where $\mathrm{Z} a / 2=1.96$

$$
\begin{aligned}
\mathrm{n} & =((1.96) 20.16(0.84)) /(0.04) 2 \\
& =322.7
\end{aligned}
$$

By adding a $10 \%$ non-response rate, the total sample size required was 355 .

Systematic random sampling technique was used to get the participants. The one month preceded case flow of each health institution was determined. Accordingly, Debre Berhan Hospital (50 cases in a month), Marie stopes private clinic (115 cases in one month) and Debre Berhan health center (45 cases in a month) were recorded. The total population in the data collection period (from September 12/2018February 12/2019) was 1050. The K interval then became 3 and the first number to start collection was selected by lottery method which was 2 . Then using the proportional sample size allocation according to 
the case flow, samples which were systematically selected from each institution were 85, 194 and 76 for Debre Berhan Hospital, Marie Stopes private clinic and Debre Berhan health center respectively.

\section{Operational definition:}

Induced abortion: Intentional termination of pregnancy by any means or person other than spontaneous (excludes miscarriage) (WHO)

Repeat induced abortion: women having more than one induced pregnancy termination defined in health care facility.

\section{Data collection instrument and process:}

Data were collected using semi-structured, pretested, and face-to-face interview in a private room at the workplace in the exit time. The questionnaire was adapted from the literatures. The tool was prepared in English and then translated into the local language, Amharic, and finally returned to English for consistency checking. Six female diploma midwives and two female degree holder midwives as supervisors were involved in the data collection process.

\section{Data quality control}

Semi-structured data collection tool was utilized and clarity of the tool was tested before the final utilization. The pretest was conducted among $5 \%$ of the sample size in the other health institution which was out of the study area. A one day training was given for data collectors and supervisors regarding the objectives of the study, data collection method and significance of the study. During data collection each data collector was supervised for any difficulties and directions and necessary corrections were provided.

\section{Data analysis}

Data were coded and entered into a computer using Epi info version 7.2.0.1. It was then checked for completeness and transferred to SPSS version 23 for analysis. Univariate analysis including mean and different frequencies were done. Crudely associated variables were identified by bivariate logistic regression model and these variables were fitted to multiple logistic regression. Then association between dependent and the explanatory variable was assessed using adjusted Odds Ratio (AOR), $95 \% \mathrm{Cl}$ and $p$-value of $\leq 0.05$ were considered statistically significant.

\section{Results}

\section{Socio-demographic characteristics}

From the selected 355 participants, a total of 345 , completed the questionnaire whereas ten refused to participate in the study, giving a response rate of $97.18 \%$. The median age of the study participants was 27 with the interquartile range of 6 . The maximum age was 40 years, and the minimum age was 17 years. Three hundred eight (89.3\%) were urban resident. One hundred eighty five (53.6\%) were college 
diploma and above as to their educational status. The Majority of the respondents, 295 (85.5\%) were followers of Orthodox Christianity. Two hundred sixty four (76.5\%) respondents were single (Table 1).

\section{Reproductive health characteristics}

From the total participants, three-hundred thirty nine (98.3\%) responded that their last pregnancy was not wanted and seventy $(20.3 \%)$ of respondents reported that they had repeat induced abortion. Eighty five of the participants $(24.6 \%)$ age of first sexual intercourse was less than eighteen years. The main reasons to have repeat induced abortion mentioned by the participants were: Economic problem (41\%), Being a student (27\%), Raped (16\%) and separated from the husband (16\%). Ninety six (27.8\%) of respondents had more than one sexual partner. Two hundred ninety one (84.3\%) respondents were ever not used family planning and three hundred nineteen $(92.5 \%)$ was planned to use family planning (Table 2 ).

\section{Associated factors of repeat induced abortion}

Crudely associated variables were: age, Place of residence, Marital status, income, Number of sexual partners, Age of first sexual intercourse, Occupation, Ever use family planning and perceiving Procedure was painful

Independently and positively associated variables in adjusted analysis were: Having more than one sexual partner in preceding 12 months, conducting sexual intercourse less than eighteen years and perceiving the previous abortion procedure as it was not painful (Table 3).

\section{Discussion}

This institutional based cross sectional study has attempted to assess the repeated induced abortion and associated factors among reproductive age women who sought abortion service in Debre Berhan town, North Shewa, Amhara region, Central Ethiopia, 2019. The study revealed that the prevalence of repeated induced abortion was $20.3 \%$ with $95 \% \mathrm{Cl}$ of $(16.4,24.3)$. This finding was in line with the study from Kenya, $16 \%(11)$.

On the other hand, this study's finding was lower than the study from Italy, $60.6 \%$ (1). This difference could be explained by the variance in a background of the study participants, variation in the study area, the cultural dissimilarity between countries, and high family planning coverage in developed countries.

This study revealed those who have more than one sexual partner in the preceding 12 months were seven times more likely to engage in repeat induced abortion when compared to those who have a single sexual partner (AOR = 7.27, 95\% Cl: 3.21,16.46). It was consistent with studies from Northern Ethiopia (16) and Cambodia (17). A possible explanation for this tendency is the increased probability of condom failure, corresponding to the increased number of sexual intercourse. The Government should continue to encourage women to define and trim down their number of sexual partners, both as a means to reduce HIV and STI transmission., 
Besides, sexual debut before 18 years was a predictor variable. $(\mathrm{AOR}=5.96,95 \% \mathrm{Cl}: 2.54,13.95)$. It was similar to the study from Northern Ethiopia (16). This might due to those who experience sexual intercourse exposed to a different sexual partner and fail to use a contraceptive. The Government should work to help adolescents delay sexual debut and encouraging family planning, including empowering communities and especially women, to freely discuss sexuality with young girls at home.

The other positive predictor of repeat induced abortion was that perceiving abortion procedure is not painful were eight times more likely to be exposed to repeated induced abortion ( $A O R=7.72,95 \% \mathrm{Cl}$ : $2.90,20.58)$. It was consistent with the study from Northern Ethiopia (16). This might due to considering the procedure not painful as well as abortion as the family planning method.

\section{Limitations}

May be affected by cross-sectional study design draw backs and comparing its findings with the community based studies may be difficult since it is institutional based.

\section{Abbreviations}

AOR: adjusted odds ratio; CSA: Central Statistical Agency of Ethiopia; FMOH: Federal ministry of health; MVA: Manual vacuum aspiration: WHO: World health organization

\section{Declarations}

\section{Ethics approval and consent to participate}

Ethical clearance was obtained from Debre Berhan health Science College. A formal letter was submitted to Debre Berhan health bureau to obtain their co-operation. The support letter was obtained from this office and submitted to Debre Berhan health Science College to get the clearance. Written consent was obtained from the study participants prior to the data collection. Moreover, all the study participants were informed verbally about the purpose and benefit of the study along with their right to refuse. Furthermore, the study participants were assured for an attainment of confidentiality for the information obtained from them and the information they gave was not with their names or any identifiers which refers to them.

\section{Consent for publication}

Not applicable because there are no individually detailed data, videos or images

\section{Availability of data and materials}

The datasets used and/or analyzed during the current study are available from the corresponding author on reasonable request.

\section{Competing interests}


We authors declare that we have no competing interests.

\section{Funding}

The article was not funded.

Authors' contributions: GKB, EAF, and GLA equally contributed to proposal development, data collection process, data management and analysis, and write up. All authors have read and approved the final manuscript.

\section{Acknowledgements}

We want to thank Debre Berhan health Science College for approving the topic, giving ethical clearance for this study. We would like to extend our thanks to the study participants for their time and willingness to participate, data collectors, and supervisors for their commitment. Our appreciation also goes to Debre Berhan health office for their cooperation and provision of supportive letters.

\section{Authors' information}

${ }^{1 *}$ Principal author: Department of Midwifery, Debre Berhan Health Sciences College, Debre Berhan, P.O. Box 37, Amhara region, Ethiopia.

${ }^{2}$ Department of basic health science, Debre-Berhan health science college, Debre-Berhan, Ethiopia

${ }^{3}$ School of Midwifery, College of Medicine and Health Science, University of Gondar, Gondar, Ethiopia

\section{References}

1. Citernesi A, Dubini V, Uglietti A, Ricci E, Cipriani S, Parazzini F. Intimate partner violence and repeat induced abortion in Italy: A cross sectional study. Eur J Contracept Reprod Heal Care [Internet]. 2015;20(5):344-9. Available from: http://www.tandfonline.com/doi/full/10.3109/13625187.2014.992516

2. A.G. M, M. W, A. E, L. C, Bankole A, Hussain R, et al. Unintended Pregnancy and Induced Abortion In Burkina Faso: Causes and Consequences. Int J Gynaecol Obstet [Internet]. 2015;14(1):1-8. Available from http://www.pubmedcentral.nih.gov/articlerender.fcgi? artid=4409713\&tool=pmcentrez\&rendertype=abstract\%5Cnhttp://www.scielo.br/scielo.php? script=sci_arttext\&pid=S0080 62342015000300495\&lng=en\&nrm=iso\&tIng=en\%5Cnhttp://www.biomedcentral.com/14712458/15/139

3. WHO. WHO I Unsafe abortion: global and regional estimates of the incidence of unsafe abortion and associated mortality in 2008. Who [Internet]. 2014;5th editio:1-67. Available from: http://whqlibdoc.who.int/publications/2011/9789241501118_eng.pdf 
4. Mosher WD, Jones J. Use of Contraception in the United States: $1982-2008$ Library of Congress Cataloging-in-Publication Data. Vital Health Stat 23. 2010. 1982-2008 p.

5. Curtis S, Evens E, Sambisa W. Contraceptive discontinuation and unintended pregnancy: An imperfect relationship. Int Perspect Sex Reprod Health. 2011;37(2):58-66.

6. Johnson BR, Ndhlovu S, Farr SL, Chipato T, Johnson BR, Farr L. and Abortion in Zimbabwe Through Postabortion Contraception. 2014;33(2):195-202.

7. Sedgh G, Singh S, Henshaw SK, Bankole A. Legal abortion worldwide in 2008: Levels and recent trends. Int Perspect Sex Reprod Health. 2011;37(2):84-94.

8. Report KI. FEDERAL DEMOCRATIC REPUBLIC OF ETHIOPIA Demographic and Health Survey.

9. Chhabra S. Unwanted pregnancies, unwanted births, consequences and unmet needs [Internet]. Vol. 1, World Journal of Obstetrics and Gynecology. 2012. p. 118. Available from: http://www.wjgnet.com/2218-6220/full/v3/i3/118.htm

10. Family Health Department. Technical and Procedural Guidelines for Safe Abortion Services in Ethiopia. 2006;(June):50. Available from: http://phe-ethiopia.org/resadmin/uploads/attachment-161safe_abortion_guideline_English_printed_version.pdf

11. Maina BW, Mutua MM, Sidze EM. Factors associated with repeat induced abortion in Kenya Global health. BMC Public Health [Internet]. 2015;15(1):1-8. Available from: http://dx.doi.org/10.1186/s12889-015-2400-3

12. Pestvenidze E, Berdzuli N, Lomia N, Gagua T, Umikashvili L, Stray-Pedersen B. Repeat induced abortions in Georgia, characteristics of women with multiple pregnancy terminations: secondary analysis of the Reproductive Health Survey 2010. Eur J Obstet Gynecol Reprod Biol [Internet]. 2016;205:85-90. Available from: http://dx.doi.org/10.1016/j.ejogrb.2016.08.020

13. Prager SW, Steinauer JE, Foster DG, Darney PD, Drey EA. Risk factors for repeat elective abortion. Am J Obstet Gynecol. 2007;197(6):1-6.

14. González-rábago Y, Rodriguez-alvarez E, Borrell LN, Martín U. The role of birthplace and educational attainment on induced abortion inequalities. BMC Public Health [Internet]. 2017;14-6. Available from: http://dx.doi.org/10.1186/s12889-016-3984-y

15. Wikipidia. Debre Berhan. In 2019.

16. Alemayehu M, Yebyo H, Medhanyie AA, Bayray A, Fantahun M. Determinants of repeated abortion among women of reproductive age attending health facilities in Northern Ethiopia: a case - control study. 2017;1-8.

17. Yi S, Tuot S, Chhoun P, Pal K, Tith K, Brody C. Factors associated with induceabortion among female entertainment workers: a cross-sectional study in Cambodia. 2015;1-8.

\section{Tables}

Due to technical limitations, the tables are only available as a download in the supplemental files section. 


\section{Supplementary Files}

This is a list of supplementary files associated with this preprint. Click to download.

- Tables.pdf 